\title{
Patterns of spirometry findings among patients with suspected lower airway obstruction in a tertiary hospital, South-South, Nigeria
}

\author{
*Jumbo, J. ${ }^{1}$, Onini, E.N. ${ }^{2}$, Okoro, T.E. ${ }^{1}$
}

\begin{abstract}
Objectives: The respiratory system consists of the upper airway and the lower airway. Although, the airway sub-serves several functions, the most important functions of the airway are ventilation and gas exchange. Lower airway obstruction by diseases such as Asthma and COPD may impair airway function. Spirometry is a useful tool in the assessment of airway function. We aim to describe the observed patterns of spirometry findings among patients with suspected lower airway obstruction at the Niger Delta University Teaching Hospital (NDUTH), Okolobiri, South-South Nigeria.
\end{abstract}

Methods: A cross-sectional study. Records of spirometry values were used to assess spirometry patterns. IBM SPSS software was used to analyze data.

Results: Spirometry records of a total 100 patients were analysed. Mean age was $48.90 \pm 19.77$ years. There were $59 \%$ males and $41 \%$ of females. Spirometry patterns were: normal-59\%; obstructive- $39 \%$; restrictive-1\%; mixed-1\%.

Conclusion: Spirometry is a useful non-invasive tool in the diagnosis of respiratory diseases, and recommended for patient evaluation in every tertiary hospital in Nigeria.

Keywords: Spirometry pattern, airway obstruction, asthma, COPD

*Corresponding author

Jumbo, J.

Email:johnbulljumbo@gmail.com

\footnotetext{
${ }^{1}$ Niger Delta Teaching Hospita (NDUTH) Okolobiri, Nigeria

${ }^{2}$ Federal Medical Centre (FMC), Yenagoa, Nigeria
} 


\title{
Modèles de résultats de spiromètre chez les patients avec suspicion d'obstruction des voies respiratoires inférieures dans un hôpital tertiaire, sud-sud, Nigéria
}

\author{
*Jumbo, J. ${ }^{1}$, Onini, E.N. ${ }^{2}$, Okoro, T.E. ${ }^{1}$
}

\begin{abstract}
Résumé
Contexte général de l'étude : Le système respiratoire comprend les voies aériennes supérieures et inférieures. Bien que les voies aériennes remplissent plusieurs fonctions, les fonctions les plus importantes des voies respiratoires sont la ventilation et l'échange de gaz. Une obstruction des voies respiratoires inférieures par des maladies telles que l'asthme et COPD peut altérer la fonction des voies respiratoires. Le spiromètre est un outil utile dans l'évaluation de la fonction des voies respiratoires. Nous visons à décrire les modèles observés de résultats de spiromètre chez les patients avec suspicion d'obstruction des voies respiratoires inférieures à l'hôpital universitaire du delta du Niger (HUDN), Okolobiri, sud-sud du Nigeria.
\end{abstract}

Méthode de l'étude : Une étude transversale. Les enregistrements des valeurs de spiromètre ont été utilisés pour évaluer les modèles de spiromètre. Le logiciel IBM SPSS a été utilisé pour analyser les données.

Résultat de l'étude : Les enregistrements de spiromètre d'un total de 100 patients ont été analysés. L'âge moyen était de 48,90 $\pm 19,77$ ans. Il y avait $59 \%$ d'hommes et $41 \%$ de femmes. Les modèles de spiromètre étaient: normal-59\%; obstructive-39\%; restrictif- $1 \%$; mixte- $1 \%$.

Conclusion : Le spiromètre est un outil non invasif utile dans le diagnostic des maladies respiratoires, et recommandée pour l'évaluation des patients dans tous les hôpitaux tertiaires du Nigéria.

Mots-clés : Schéma de spiromètre, obstruction des voies respiratoires, asthme, COPD

*Corresponding author

Jumbo, J.

Email: johnbulljumbo@gmail.com

\footnotetext{
${ }^{1}$ Niger Delta Teaching Hospita (NDUTH) Okolobiri, Nigeria

${ }^{2}$ Federal Medical Centre (FMC), Yenagoa, Nigeria
} 


\section{INTRODUCTION}

The respiratory tract can be divided on the basis of anatomical location into the upper airway and the lower airway (1). Although, the airway subserves several functions, the most important functions of the airway are ventilation and gas exchange (2). In health, efficient functioning of the airways is usually maintained by their patency at all times. However, this is not always the case as the airways can face insult resulting from different pathologic processes that eventually lead to limitation of airflow, and hence impair gas exchange $(3,4)$. Lower airway obstruction is most commonly caused by Asthma and Chronic Obstructive Pulmonary Disease (COPD) $(5,6)$. Less common causes are Bronchiectasis, Bronchiolitis, Cystic Fibrosis and bullous disease of the lungs. Common presentations of lower airway obstruction include cough, difficulty with breathing, chest tightness, wheeze and other features relating to the cause of the airway obstruction.

A number of studies have examined the burden obstructive airway diseases in different parts of Nigeria. Umoh VA, in 2012, published an overview of chronic obstructive pulmonary disease (COPD): Epidemiology and Pathogenesis (7). In this study, a review of available literature on COPD was done via medline and google search. He noted that the prevalence of COPD is increasing especially in developing countries. As part of the BOLD I study (8), Obaseki and colleagues examined the prevalence of COPD in Ile-Ife. The researchers reported a COPD prevalence of $0.3 \%$ in Ile-Ife, and concluded that COPD is highly underdiagnosed and consequently undertreated in Ile-Ife, Nigeria. In an earlier study on the burden of respiratory disease in Nigeria by Akanbi et al (9), COPD and Asthma topped the non-infectious diseases in their classification of respiratory disease burden in Nigeria. In another study, Adeniyi et al, investigated the pattern of respiratory disease admissions among adults at the federal medical centre, Owo, South-West, Nigeria. Of 502 respiratory admissions examined at the time, $13.7 \%$ were COPD patients while $8.4 \%$ were Asthma patients (10).

Spirometry is an essential tool for assessing airway obstruction, and to ascertain whether airway obstruction is reversible (as in Asthma) or irreversible (as in COPD) (11). As a basic lung function test that measures both inhaled and exhaled air (11), it is also useful in differentiating obstructive airway disease from restrictive lung disease. Other indications for spirometry include pre-operative assessment of patients as well as pre-employment evaluation. Spirometry is objective, noninvasive, sensitive to early changes in airway pathology and reproducible when performed according to standard guidelines (12).

During Spirometry, participants are usually instructed to either stand or sit comfortably while they inspire fully, occluding their nostrils with a nose clip. They are then told to place the mouthpiece of the spirometer in their mouth, and seal their lips around the mouthpiece. This is followed by breathing out as fast as they could without blocking the flow of air with their tongue until the lungs get empty (13). The maneuver is done both before and after administration of a standard dose of a shortacting bronchodilator such as salbutamol using a metered-dose inhaler with a spacer device. The acceptability criteria as per ATS/ERS are: good start, characterized by back extrapolated volume less than $5 \%$ of the FVC or $0.15 \mathrm{~L}$, whichever is greater, freedom from artefacts such as cough, sneezing and glottis closure, and a good end, characterized by absence of early termination with spirogram showing satisfactory expiratory time of 6 seconds or more, or by manual recognition of at least a plateau in the volumetime curve. The highest of three spirograms which meet the ATS/ERS acceptability criteria is usually chosen for evaluation of lung function (14).

Industrial operations such as oil and gas exploration are frequent in Bayelsa State, Nigeria with repeated exposures of the inhabitants to gas flaring. Repeated exposure to gas flaring has been linked with the development of abnormal spirometry parameters such as reduction in FEV1 and PEF $(15,16$,). However, no such studies have been conducted in Bayelsa State. We therefore, aim to describe the observed patterns of spirometry findings among patients with suspected lower airway obstruction at the Niger Delta University Teaching Hospital (NDUTH), Okolobiri, south-south Nigeria.

\section{MATERIALS AND METHODS}

The study was a hospital-based observational cross-sectional study. It was a retrospective study involving the assessment of spirometry patterns over a two-year period (January 2018 to December 2019). The study was conducted on the spirometry records of all adult patients with suspected lower airway obstruction during the study period, who were referred for spirometry at the Cardiopulmonary laboratory of 
the Niger Delta University Teaching Hospital (NDUTH), Okolobiri. Sources of patients were the respiratory clinic of the hospital, referrals from other clinics and departments of the hospital and referrals from other hospitals for assessment of lung function at the Niger Delta University Teaching Hospital (NDUTH), Okolobiri. Information on spirometry findings were obtained from the record book of the spirometry section of the cardiopulmonary laboratory of the hospital, which uses a standard spirometer (MIR Spirolab III) for spirometry in line with the current ERS/ATS guidelines. ${ }^{11}$ The findings of spirometry were classified as normal pattern (FEV1/FVC $>70 \%$; FVC $>80 \%$ of predicted), obstructive pattern (FEV1/FVC $\leq 70 \% \&$ FEV 1 $<80 \%$ of predicted), restrictive pattern (FEV1/FVC $>70 \% \&$ FVC $<80 \%$ of predicted) and mixed pattern (FEV1/FVC $<70 \% \& \mathrm{FVC}<$ $80 \%$ predicted).

\section{Data analysis}

Data was analysed using IBM SPSS Statistics 25. Patient demographics and spirometric patterns were analysed using descriptive statistics and presented on charts and tables as percentages.

\section{RESULTS}

\section{Age and gender distribution of the patients}

The spirometry findings of a total of 100 adults were analysed for the study. The mean age of the patients was $48.90 \pm 19.77$ years. More patients were within the ages of 41 and 50 years as shown in figure 1 . The gender distribution of the patients was comparable, though males were slightly more $(51 \%)$ than females $(49 \%)$ as shown in figure 2.

\section{Indications for spirometry}

Table 1 shows the indications for spirometry in the study. Almost two-thirds (59\%) were cases of suspected Asthma; $26 \%$ were cases of suspected chronic obstructive pulmonary disease; while

other suspected lower airway obstructive conditions accounted for $15 \%$ of the cases.

\section{Patterns of spirometry findings}

General spirometry patterns: Majority (59\%) of the patients had a normal pattern, while the remainder had abnormal patterns; 39\% had obstructive pattern, while $1 \%$ had restrictive and mixed patterns respectively (figure 3 ).

Age-related spirometry patterns: Table 2 shows that normal spirometry pattern is more among those between the ages of 41 and 50 years $(15 \%)$, while obstructive pattern is more among those between the ages of 51 and 60 years (11\%). Other age-related patterns are shown in table 2.

Gender-related spirometry patterns: From table 3 , more males had normal spirometry pattern $(32 \%$ vs $27 \%)$ while more females had obstructive pattern (21\% vs $18 \%)$. Only a single male $(1 \%)$ had a mixed pattern while only a single female $(1 \%)$ had a restrictive pattern.

\section{DISCUSSION}

Our study tried to assess the spirometry patterns in suspected cases of lower airway obstruction. The study revealed that all the spirometric patterns were present with normal and obstructive patterns respectively being the more prevalent patterns by far. These findings are similar to that found in a study by Nnamdi et al, which was also a hospital-based study that investigated the utility of spirometry in assessment of presumptive diagnosis of bronchial Asthma in a Nigerian tertiary hospital[17]. In that study, the authors demonstrated that all the ventilatory patterns were present with the highest percentage being normal followed by obstructive pattern.

This study shows that although many referrals are made for spirometric assessment of patients presenting with respiratory symptoms suggestive of lower airway obstruction, not all patients eventually met the criteria for the diagnosis of airway obstruction. Notwithstanding the study was still relevant considering the percentage that had obstructive pattern (39\%). Obstructive lung diseases have been recognized to be of global disease burden, especially COPD and Asthma. For instance, the global initiative for obstructive lung disease, projected that chronic obstructive pulmonary disease (COPD) will be the third leading cause of death in the world in 2020[18]. ${ }^{13}$ Also, the 2018 global Asthma report[19], states that Asthma is one of the most common chronic diseases worldwide, affecting about 358 million people worldwide with about 250,000 deaths worldwide. Therefore, spirometric assessment of patients becomes pertinent as it would aid in prompt diagnosis and prevention of obstructive airway disease.

In our study, restrictive and mixed patterns were insignificant ( $1 \%$ each). This could further validate the suspicion of airway obstruction in these patients. The finding of 
normal spirometry pattern can be traced to some explanations. First, even with the presence of obstructive airway disease such as Asthma, normal spirometry patterns are frequent[20]. This is because the attacks of asthma are episodic. This implies that conducting spirometry during an attack-free period may produce a normal rather than obstructive pattern. Secondly, some patients with asthma may have obstructive spirometry pattern but may have been on regular medications such as inhaled corticosteroids, that may have offered good control of their disease. This may tilt the spirometry pattern to normal rather than obstructive. Moreover, there may be other conditions in these patients that are known to present with symptoms suggestive of lower airway obstruction but normal spirometry. These conditions include upper airway cough syndrome, hyperactive airway syndrome, reactive airway dysfunction syndrome and vocal cord pathologies.

Our study also showed that about twothirds of those with normal spirometry pattern are within the ages of 50 years and below (relatively younger age groups). However, we note a reversal of this pattern in the case of obstructive findings, in which, a higher percentage of the obstructive pattern was observed in the older subpopulation. This is rather not surprising because advancing age is a risk factor for obstructive lung diseases such as COPD[21]. This means that majority of those with obstructive pattern may be cases of COPD. Also, the fact that a relatively younger subpopulation had normal spirometry pattern may be explained in part by the fact that young people have better lung function than older people[22]. On the other hand, since Asthma is believed to be more prevalent in younger persons compared to COPD, this group may represent a set of persons with Asthma but had a normal spirometry for one or two of the reasons earlier pointed out. Further studies may be necessary to validate these claims.

Gender-related patterns were also observed from the findings of the study. The study findings showed that more than half of those with normal pattern were males, whereas more than half of those with obstructive pattern were females. In health, gender differences in pulmonary function have always favored males (23). Although COPD is known to be more prevalent in males due to a greater prevalence of cigarette smoking, this trend is changing as more females now engage in cigarette smoking. In developing countries, indoor air pollution from use of biomass has been suggested to be contributing to COPD in females $(24,25,26)$. Furthermore, asthma is more prevalent in females $(27,28)$. These facts may explain the genderrelated findings in the study.

It is worth noting that the findings in this study are not intended to be used for making generalizations, but underscore the usefulness of spirometry in the evaluation of patients presenting with symptoms of lower airway obstruction.

\section{CONCLUSION}

Spirometry is a useful non-invasive tool in the diagnosis of respiratory diseases. Our study showed all the four patterns among the study population. Normal spirometry pattern was the commonest overall, but obstructive pattern was the commonest ventilatory defect.We recommend that spirometry should be a basic tool for patient evaluation in all tertiary hospitals in Nigeria.

Limitations: The study relied on records of spirometry, which was not personally done by the researchers. Also, the sample size may not be large enough for generalization of findings. Finally, other aspects of spirometry such as reversibility testing was not reported in this study.

Financial support and sponsorship: Nil.

\section{Conflict of interest: $\mathrm{Nil}$}

\section{REFERENCES}

1. Brewis RAL, White FE. Anatomy of the thorax. In: Gibson GJ, Geddes DM, Costabe IU, Sterk PJ, Corrin B. Respiratory Medicine. Edinburgh: Elsevier Science, 2003:3-33.

2. Lumb AB. Nunn's Applied Respiratory Physiology. 7th Edn. London, Elsevier, 2010.

3. David VT. Pathophysiology and causes of airflow limitation. In: Andrew W, Simon F, Derek CA, Mervyn S; Oxford textbook of critical care, 2ed, 2016; ISBN: 9780199600830.

4. Niewoehner DE. Clinical practice. Outpatient management of severe COPD. New England Journal of Medicine, 2010;362 (15): 1407-1416.

5. Bardin PG, Johnson SL, Hamilton G. Middle airway obstruction-under our noses. Thorax 2013; 68: 396-398.

6. Fabbri LM, Romagnoli M, Corbetta L, Casoni G,Busljetic K, Turato G, et al. Differences in airway inflammation in patients with fixed airflow obstruction due to asthma or chronic obstructive pulmonary disease. Am J Respir Crit Care Med; 2003; 167: 418-424. 
7. Victor AU. An overview of chronic obstructive pulmonary disease (COPD): Epidemiology and Pathogenesis. Nigerian health journal, 2012; 12 (3): 53-64.

8. Daniel O, Erhabor GE, Peter B, Sonia B, Olayemi A, Louisa G. The prevalence of COPD in an African city: results of the BOLD study, Ile-Ife, Nigeria. European Respiratory Journal 2013; 42: 932.

9. Akanbi MO, Ukoli CO, Erhabor GE, Akanbi FO, Gordon SB. The burden of respiratory disease in Nigeria. African Journal of Respiratory Medicine, 2009

10. Adeniyi BO, Awokola BI, Irabor I, Obaseki DO, Ayeni EO, Alele BK, et al. Pattern of respiratory disease admissions among adults at the federal medical centre, Owo, South-West, Nigeria: a 5year review. Ann Med Health Sci Res. 2017; 7: 96 101.

11. Miller MR, Hankinson J, Brusasco V, Burgos F, Casaburi R, Coates A, et al. Standardization of spirometry. Eur Respir J2005; 26: 319-338.

12. Coates AL, Graham BL, McFadden RG, McParland C, Moosa D, Provencher S, et al. Canadian Thoracic Society. Spirometry in Primary care. Can Respir J2013; 20: 13-21.

13. Brian LG, Irene S, Miller MR, Igor ZB, Brendan GC, Graham LH, et al. Standardization of spirometry 2019 update: An official American Thoracic Society and European Respiratory Society Technical Statement. American Journal of Respiratory and Critical Care Medicine, 2019; 200:8.

14. Erhabor G. pulmonary function tests: spirometry and peak flow in clinical practice; 2010; p18-26. ISBN 978-8139-67-1.

15. Ovuakporaye SI, Aloamaka CP, Anthony O, Daniel E, Joseph CM. Effect of Gas Flaring on Lung Function among Residents in Gas Flaring Community in Delta State, Nigeria. Res J Environ Earth Sci, 2012; 4(5):525-528.

16. Ovuakporaye SI, Igweh CJ, Aloamaka CP. Impact of Gas Flaring on Cardiopulmonary Parameters of Residents in Gas Flaring Communities in Niger Delta Nigeria. British Journal of Medicine \&
Medical Research, 2016; 15(6): 1-13.

17. Nnamdi N, Chinwe C, Cajetan CO, Adaeze CA, Hilary CO, Paul IN. The utility of spirometry in assessment of presumptive diagnosis of bronchial asthma in a Nigerian tertiary hospital. Indian Journal of respiratory Care, 2019; 8 (2): 1-5.

18. Global Initiative for Obstructive Lung Disease. Pocket guide to COPD diagnosis, management and prevention; a guide for health care professionals, 2020. www.goldcopd.org

19. Guy M, Neil P, David S, Innes A, Philippa E. Global burden of disease due to Asthma. In: Global Asthma Report, 2018.

20. McCormack MC, Enright PL. Making the diagnosis of asthma. Respir Care. 2008; 53(5): 583-592.

21. Global Initiative for Chronic Obstructive Lung Disease. Global Strategy for Diagnosis, Management, and Prevention of COPD 2012. www.goldcopd.org

22. Gulshan S, James G. Effect of aging on respiratory system physiology and immunology. Clinical interventions in Aging, Dove Medical Press, 2006; 1 (13): 253-260.

23. LoMauro A, Aliverti A. Sex differences in respiratory function. Breathe 2018; 14: 131-140.

24. Viegi G, Simoni M, Scognamiglio A, Baldacci S, Pistelli F, Carrozzi L, et al. Indoor air pollution and airway disease. Int J Tuberc Lung Dis 2004; 8:1401-1415.

25. Bruce N, Perez-Padilla R, Albalak R. Indoor air pollution in developing countries: a major environmental and public health challenge. Bull World Health Organ 2000; 78:1078-1092.

26. Desai M, Mehta S, Smith K. Indoor smoke from solid fuels: assessing the environmental burden of disease at national and local levels. Geneva, Switzerland: World Health Organization; 2004.

27. Fuseini H, Newcomb DC. Mechanisms driving gender differences in asthma. Curr Allergy Asthma Rep 2017; 17 (3): 19.

28. Zein JG, Erzurum SC. Asthma is different in women. Curr Allergy Asthma Rep 2015; 15 (6): 28.

How to cite this article:

Jumbo, J., Onini, E.N., Okoro, T.E. Patterns of spirometry findings among patients with suspected lower airway obstruction in a tertiary hospital, South-South, Nigeria. Research Journal of Health Science, 2021,9(1): 61-68 


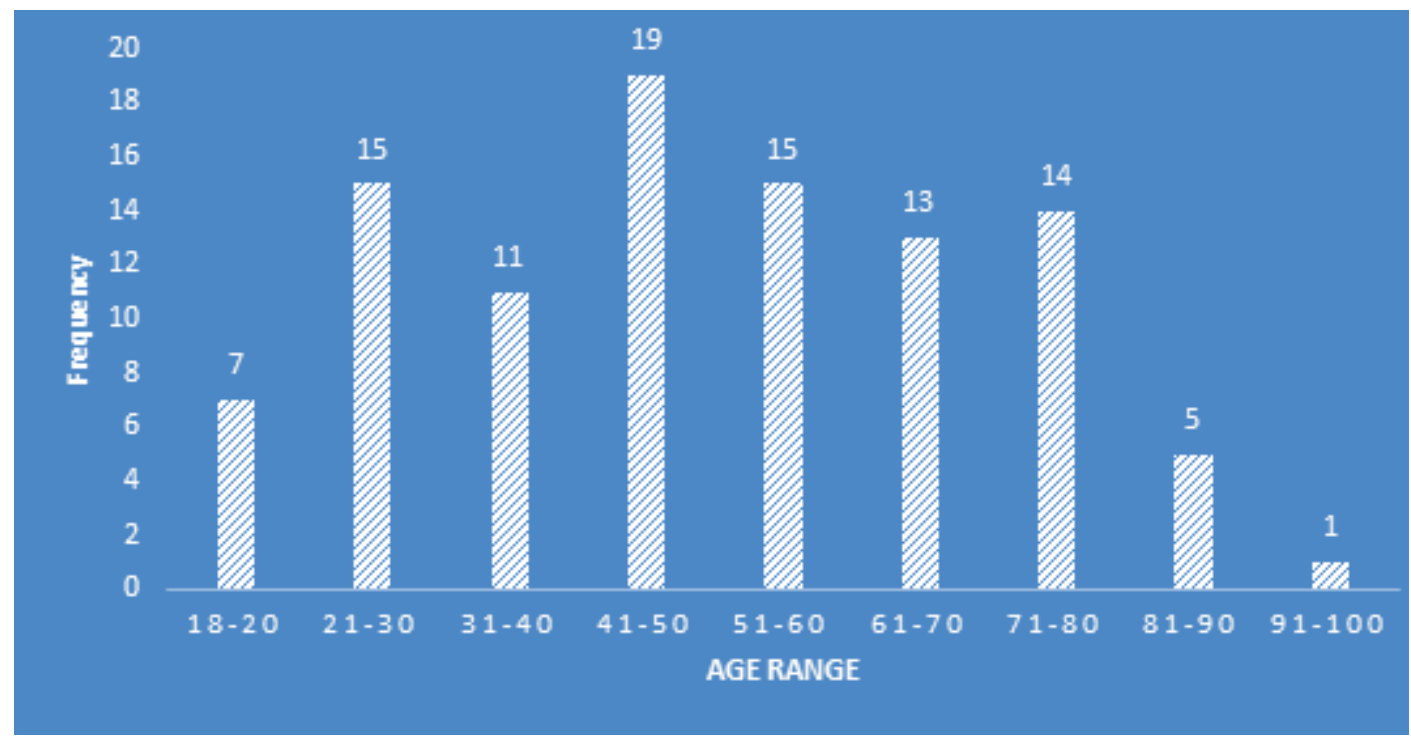

Figure 1; Bar chart showing the age distribution of patients.

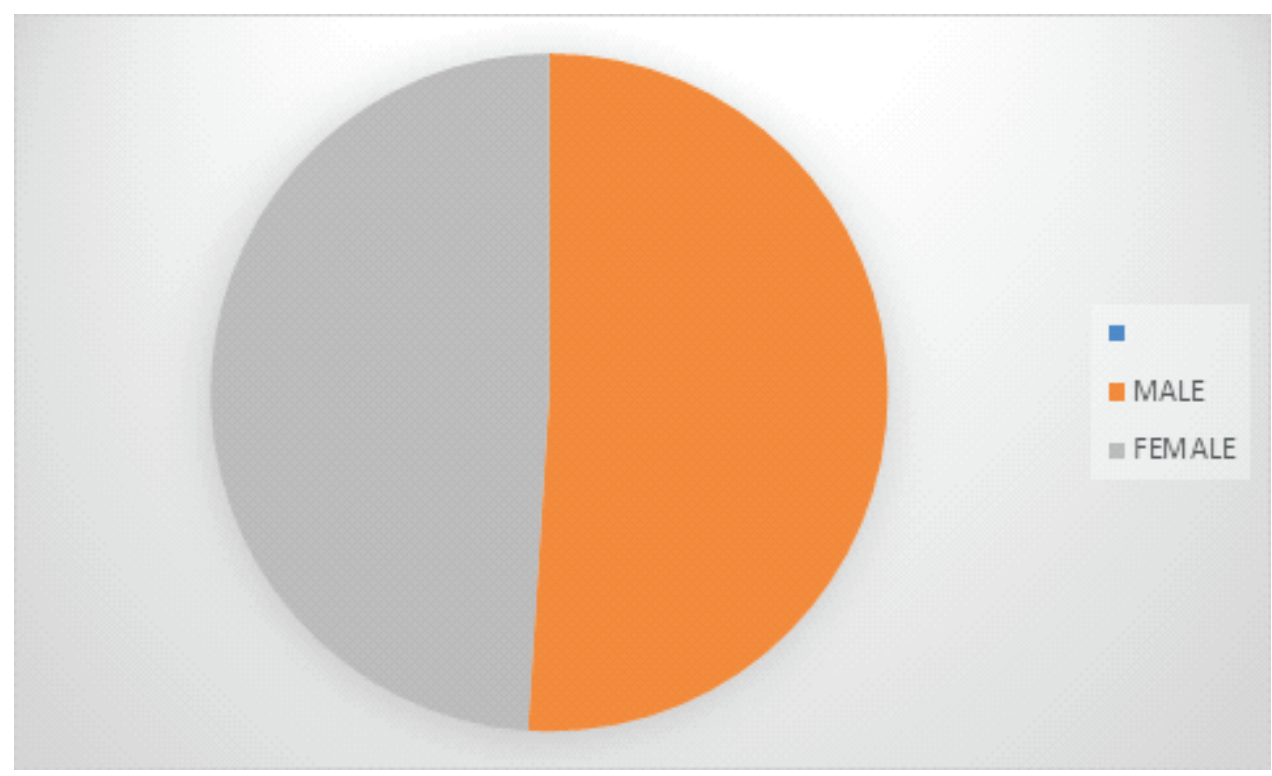

Figure 2; Pie chart showing the gender distribution of the patients

Table 1; Indications for spirometry in the study

\begin{tabular}{ll}
\hline Indication for spirometry & Frequency (\%) \\
\hline Suspected Asthma & 59 \\
Suspected COPD & 26 \\
Bronchiectasis & 9 \\
Bronchiolitis & 3 \\
Pre-op evaluation & 3 \\
Total & 100 \\
\hline
\end{tabular}




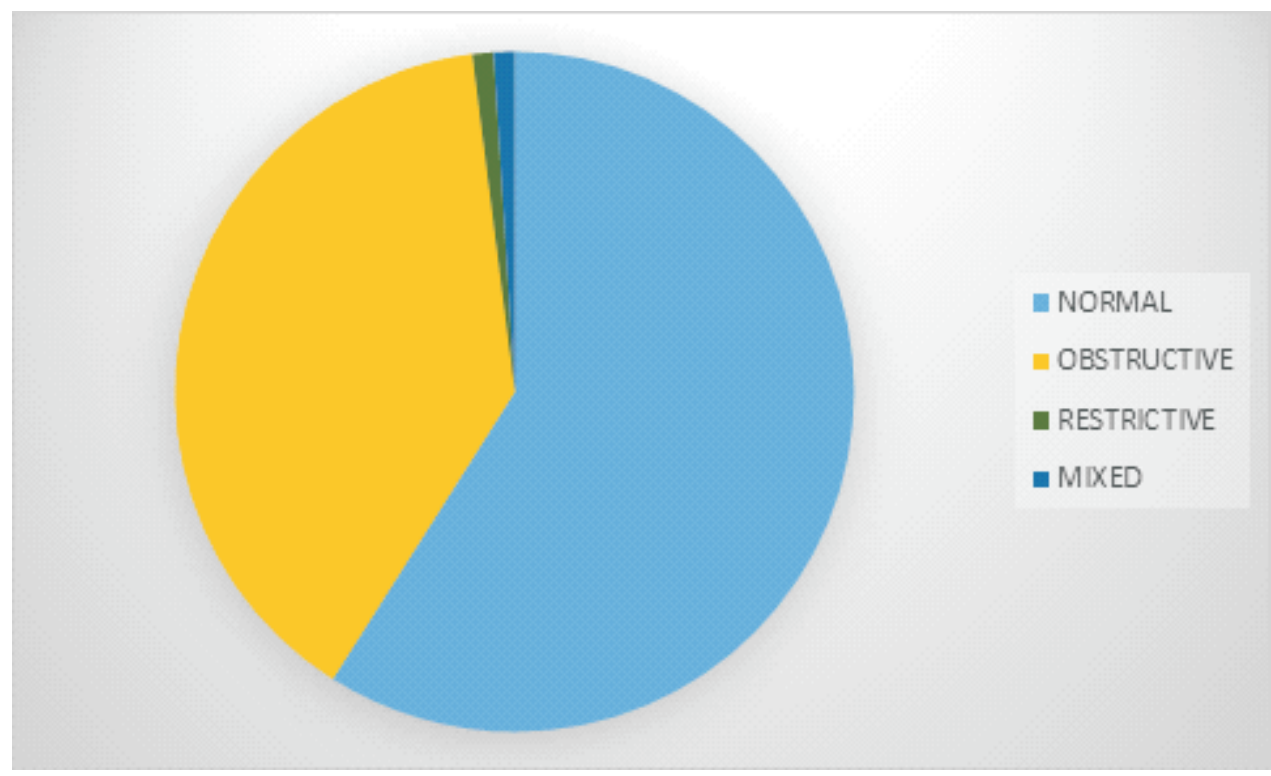

Figure 3; Pie chart showing the pattern of spirometry findings among patients.

Table 2; Age-related distribution of spirometry patterns among the study population.

\begin{tabular}{llllll}
\hline $\begin{array}{l}\text { Age range } \\
\text { (years) }\end{array}$ & \multicolumn{2}{l}{ Spirometry pattern } & & Total \\
\cline { 2 - 5 } & $\begin{array}{l}\text { Normal } \\
(\%)\end{array}$ & $\begin{array}{l}\text { Obstructive } \\
(\%)\end{array}$ & $\begin{array}{l}\text { Restrictive } \\
(\%)\end{array}$ & $\begin{array}{l}\text { Mixed } \\
(\%)\end{array}$ & \\
\hline $\mathbf{1 8 - 2 0}$ & 6 & 1 & 0 & 0 & 7 \\
$\mathbf{2 1 - 3 0}$ & 11 & 4 & 0 & 0 & 15 \\
$\mathbf{3 1 - 4 0}$ & 7 & 4 & 0 & 0 & 11 \\
$\mathbf{4 1 - 5 0}$ & 15 & 2 & 1 & 1 & 19 \\
$\mathbf{5 1 - 6 0}$ & 4 & 11 & 0 & 0 & 15 \\
$\mathbf{6 1 - 7 0}$ & 8 & 5 & 0 & 0 & 13 \\
$\mathbf{7 1 - 8 0}$ & 6 & 8 & 0 & 0 & 14 \\
$\mathbf{8 1 - 9 0}$ & 2 & 3 & 0 & 0 & 5 \\
$\mathbf{9 1 - 1 0 0}$ & 0 & 1 & 0 & 0 & 1 \\
Total & 59 & 39 & 1 & 1 & 100 \\
\hline
\end{tabular}

